\title{
A METHODOLOGY FOR EVALUATING USER PERCEPTIONS OF THE DELIVERY OF ICT SERVICES: A COMPARATIVE STUDY OF SIX UK LOCAL AUTHORITIES
}

\author{
Les Worrall, Dan Remenyi and Arthur Money \\ Prof. Les Worrall, Associate Dean (Research), Management Research Centre, Wolverhampton Business School, University of \\ Wolverhampton, Telford Campus, Telford, TF2 9NT, UK. I.worrall@wlv.ac.uk \\ Prof. Dan Remenyi, Visiting Professor, Department of Information Systems and \\ Computing, Brunel University, Uxbridge, Middlesex UB8 3PH, UK. Address for correspondence: Remenyi@Compuserve.com \\ Prof. Arhur Money, Henley Management College, Greenlands, Henley on Thames, Oxfordshire, RG9 3AU, UK \\ Arthur.M@henleymc.ac.uk
}

\begin{abstract}
:
Evaluating and managing the effective delivery of ICT services is an issue that has been brought into sharper relief recently. This has been particularly prevalent in the UK public sector where the growing emphasis on formalised client-contractor relationships, outsourcing and benchmarking (both between local authorities and between local authorities and private sector organisations) has meant that the definition of service standards and agreeing performance criteria has attracted considerable practitioner attention.

This research is based on 295 interviews conducted in six UK local authorities. The investigation used both gap analysis and perceptual mapping techniques to develop an understanding of the aspects of ICT service delivery that users' value most in conjunction with an assessment of how well they perceive their ICT department is performing on these criteria. The paper exposes considerable differences in the relative performance of the six local authorities from both the gap analysis and the penceptual mapping elements of the investigation. The methodology is shown to provide an effective way of identifying key performance issues from the user perspective and benchmarking service performance across organisations
\end{abstract}

\section{INTRODUCTION}

This paper proposes a methodology for evaluating the performance of an Information and Communications Technology (ICT) department or service provider. Although the research has been conducted within UK local government, we propose a methodological framework for the evaluation of effectiveness of ICT service delivery, incorporating the views of all the main stakeholders, which we believe is generally applicable. This subject is important because it is increasingly clear that the current approaches to managing ICT and managing ICT departments have not always produced satisfactory results. Specifically, computer systems take too long to develop, user departments often voice their dissatisfaction with the quality and timeliness of support they receive, systems often run over budget (Allingham and O'Connor 1992; Lester and Willcocks, 1993; Banker and Kemerer 1991; Remenyi, 1991) and systems are frequently perceived not to deliver the benefits on which they were originally business-justified (Attewell 1993; Brynjolfsson 1993; Wilson 1993; Peters 1988; Parker, 1989; Hitt and Brynjolfsson 1994; Remenyi et al. 1997; Remenyi et al. 2000; Willcocks 1991). These circumstances are not new and they have been a central challenge for ICT management and the management of useroriented ICT services for the past thirty years: they continue to be a major problem in many organisations today.

The ICT function of an organisation is involved in the development, implementation and maintenance of numerous information technologies and systems and supporting a wide range of users of differing ability and ICT awareness. More important, certainly in the UK, the power in the user-provider relationship has moved significantly from the provider to users as initiatives such as "market testing", "compulsory competitive tendering" and "best value" have been introduced in UK central and local government (see Goss et al, 1993 for a description of these terms). The information systems in most organisations aim to meet needs at all levels within the organisation from operational, through tactical to strategic. In evaluating the success or effectiveness of the ICT department it is necessary to evaluate the performance of the individual systems and the performance of the ICT department in supporting the users of those systems. In addition, it is important to assess users' overall view of the effectiveness of the ICT department (Silk, 1990). However, in recent years, and particularly in local government, users have become far more concerned about the effective delivery of an ICT service and, in many instances, this has become enshrined in the production of service level agreements negotiated between ICT users and the service providers. In addition to assessing satisfactions with systems, and given the changes in power relationships, we also need to be able to assess satisfaction with the broader quality of service provided defined on parameters of most relevance to the user. 
There have been continuous attempts to improve both the efficiency and effectiveness with which computer systems are conceptualised, developed and commissioned: although considerable progress has been made the situation is still fraught with many problems (Remenyi and Money, 1991; Remenyi and Money 1993; Remenyi et al., 1997; Remenyi et al., 2000). However, the problems identified require urgent resolution as it becomes more and more apparent that traditional information systems methods and traditional, provider-oriented approaches to service management and service delivery no longer fit the way organisations need to conduct their business in an ever increasingly competitive environment.

From a functional perspective, which has implications for managing the ICT service, local authorities in the UK are highly complex organisations (Worrall, 1994; 1995). It has been estimated that each year, collectively, local government spends over $£ 1$ billion on information technology (SOCITM, 1996). This is a substantial sum, yet, apart from regular analysis by the Audit Commission, we are unaware of any systematic cross-local authority comparisons of how the users of ICT view the relative importance of aspects of their organisation's ICT management policies or how satisfied they are with how their organisation performs on those criteria. The research presented here moves some way to filling this gap in our knowledge and is based on questionnaire interviews with ICT users in six local authorities. The interviews were completed in September 1997 and used a variant of a questionnaire that had been designed and tested elsewhere (see Remenyi and Money, 1991; 1993).

This paper comprises seven main sections. The first section contains a description of the approach used to collect the data and a description of the respondents to the sample in terms of their level in the organisation and their intensity of use of ICT. The second section contains an analysis of responses on the importance of attributes affecting IS/T effectiveness and a user assessment of organisational performance on these attributes. The third section uses factor analysis to highlight key themes in both the importance and performance data. The key importance factors are then used to compare the performance of local authorities. In the fourth section, the relationship between an organisation's performance on the importance composite variables produced by the factor analysis are compared in order to assess the performance. In the fifth main section, the local authorities are compared based on their scores on the eight derived variables. In the sixth section, a cross-local authority analysis of a number of attitudinal variables is conducted in order to try to explain some of the differences in performance across local authorities that the analysis has exposed. In the seventh, and final main section, there is an analysis of the open responses which the questionnaire sought to obtain. This final section is based on a content analysis of the open responses to which correspondence analysis (Greenacre, 1994; Remenyi and Money, 1994) has been applied in order to identify similarities between local authorities and the issues that users have identified within them. The concluding section summarises the main findings and discusses the responses of the ICT directors of the six participating local authorities to the findings following a debriefing session held with them on the outcomes of the research.

\section{THE APPROACH TO EVIDENCE COLLECTION}

The research project uses a previously validated self-completion questionnaire. The questionnaire was developed in an earlier study (Remenyi and Money, 1994): the attributes included with it (see Table 2) were derived from a review of existing literature, from the authors' extensive experience in ICT management and from discussions with users prior to the implementation of the initial study. Prior to the execution of the study reported here, consultations were held with several IT experts from UK local government and the IT directors from the six participating local authorities. On the basis of this the attributes derived from Remenyi and Money's 1994 study were modified slightly to reflect the UK local government context.

The analytical techniques used include satisfaction-importance gap analysis as developed by Parasruraman et al. (1985) to explore levels of user satisfaction and user assessed importance of attributes and established techniques such as regression analysis, factor analysis (Lehmann 1989; Kerlinger 1969) and correspondence analysis (Greenacre 1984). These techniques are used to develop an understanding of the perceptions which shape and underpin user satisfaction (see Hair et al, 1998). Much of the data collected was derived using Likert scales and we are aware of the problems that may arise using regression and factor analysis on this type of data. However, this form of analysis now seems to have become commonplace in much management research literature. 
Given the perennial problem of gaining access to organisations in business and management research, initial contact was made through the Society of Information Technology Managers to six local authorities who then agreed to participate in the study: they have been given the fictitious names of the London Borough of Banton, Dunton County Council, Eston County Council, Posham Unitary Council, Wrenton Unitary Council and Brinton District Council. The local authorities included in the exercise thus represent a variety of types and sizes of local authority. The data collection process was completed in September 1997. The number of respondents from each local authority is shown in Table 1.

Table 1: Responding local authorities and the number of responses

\begin{tabular}{|l|l|r|}
\hline Local authority & Type of local authority & Responses \\
\hline Banton & London Borough & 52 \\
\hline Brinton & District Council & 52 \\
\hline Dunton & County Council & 49 \\
\hline Eston & County Council & 82 \\
\hline Posham & Unitary Authority & 31 \\
\hline Wrenton & Unitary Authority & 29 \\
\hline Total & & 295 \\
\hline
\end{tabular}

The questionnaire comprised seven major sections. The first part sought information about the respondents such as their level in the organisation, their years of experience working with ICT, their intensity of use of ICT and 'how comfortable' they felt using ICT. The second section asked respondents to rate (using a six point Likert scale) how important each of thirty eight attributes were in ensuring the effective delivery of their organisation's IS/T strategy and IS/T service (see Table 2 for a list of the attributes). The third section asked respondents to rate (using a six point Likert scale) their organisation's performance on the same thirty eight attributes. In sections four and five respectively, respondents were asked to identify how intensively they used various systems in their organisation and how effective they thought those systems were. The sixth section contained questions to identify how well users had been involved in the process of IS/T development; how well existing ICT met users' managerial and operational needs; users' satisfaction with the training they had received; users' views on how well service level agreements work; and, users' overall opinion of their ICT department. The final section gave the users the opportunity to state how they thought the effectiveness of the IS/T service in their organisation could be improved using an open ended question.

\section{AN ASSESSMENT OF THE IMPORTANCE ATTRIBUTES AFFECTING ICT EFFECTIVENESS AND A USER ASSESSMENT OF ORGANISATIONAL PERFORMANCE ON THESE ATTRIBUTES}

The main objective of the research was to identify the degree of importance that users ascribed to each of thirty eight attributes integral to the design, development and delivery of an IS/T strategy in their local authority. The mean score on each of the thirty eight attributes was calculated and the attributes were then ranked to give an impression of the relative importance that users ascribed to each of the attributes. The results of this analysis, ranked by the perceived importance of attributes, are shown in Table 2. It is noticeable that the most highly rated attributes related, not to the technological components of the IS/T strategy, but to the 'softer' aspects of the IS/T strategy such as a high degree of technical competence from support staff, ease of access to facilities, fast response from support staff to remedy problems, user confidence in systems and a positive attitude by support staff to users. The majority of the top ten rated attributes were related to the quality of the support service that the ICT department provided.

A second task was to measure how well users' perceived their organisation's $1 S / T$ strategy to be performing on the same thirty eight attributes. The average performance score and the average importance score on each of the thirty eight attributes are shown in Table 2. A trace of these scores, both performance and importance, for each of the thirty eight attributes is shown in Figure 1. 
Table 2: Respondent's assessment of the importance of each attribute and an assessment of current performance.

\begin{tabular}{|c|c|c|}
\hline Attribute & $\begin{array}{l}\text { Importance } \\
\text { Mean score }\end{array}$ & $\begin{array}{l}\text { Performance } \\
\text { Mean score }\end{array}$ \\
\hline A high degree of technical competence in systems support staff. & 5.6 & 4.2 \\
\hline Ease of access for users to computing facilities. & 5.5 & 4.5 \\
\hline User confidence in systems. & 5.5 & 3.9 \\
\hline Fast response time from systems support staff to remedy problems. & 5.5 & 3.8 \\
\hline Provision for disaster recovery. & 5.3 & 3.6 \\
\hline Positive attitude of information systems/ICT staff to users. & 5.3 & 4.2 \\
\hline A low percentage of hardware and software downtime. & 5.2 & 3.9 \\
\hline System's response time. & 5.2 & 3.9 \\
\hline Systems responsiveness to changing user needs. & 5.1 & 3.5 \\
\hline Extent of user training. & 4.9 & 3.3 \\
\hline Participation in the planning of the system's requirements. & 4.9 & 3.6 \\
\hline Users' understanding of the system. & 4.9 & 3.7 \\
\hline Ability of the system to improve personal productivity. & 4.9 & 4.1 \\
\hline The quality of the reports delivered to the user. & 4.9 & 4.1 \\
\hline The use of Windows type software. & 4.8 & 4.6 \\
\hline Systems analysts who know the user's business. & 4.8 & 3.5 \\
\hline Flexibility of the system with regards to both data and reports. & 4.8 & 3.7 \\
\hline Users' willingness to find time to learn the system. & 4.7 & 3.7 \\
\hline Prompt processing of requests for changes to the existing systems. & 4.7 & 3.4 \\
\hline Up-to-dateness of software. & 4.6 & 4.1 \\
\hline Confidentiality of user's own data. & 4.6 & 4.4 \\
\hline $\begin{array}{l}\text { Flexibility to produce professional reports (e.g. graphics and desktop } \\
\text { publishing). }\end{array}$ & 4.6 & 3.9 \\
\hline Overall cost-effectiveness of information systems. & 4.6 & 3.6 \\
\hline $\begin{array}{l}\text { The monitoring of the ICT Department's performance in delivering } \\
\text { services to users. }\end{array}$ & 4.6 & 3.1 \\
\hline $\begin{array}{l}\text { The alignment of the information systems plan with the overall } \\
\text { corporate plan. }\end{array}$ & 4.6 & 3.4 \\
\hline Up-to-dateness of hardware. & 4.5 & 4.1 \\
\hline Documentation to support training. & 4.5 & 3.5 \\
\hline The degree of personal control users have over their systems. & 4.3 & 3.7 \\
\hline Procedures for avoiding software piracy. & 4.2 & 3.6 \\
\hline Short lead times for the development of new systems. & 4.2 & 2.8 \\
\hline The measurement of benefits derived by the user from the system. & 4.2 & 3.1 \\
\hline Ability of the system to enrich the working experience of the user. & 4.1 & 3.8 \\
\hline Help with database or data model development. & 4.1 & 3.2 \\
\hline Standardisation of hardware. & 3.9 & 3.6 \\
\hline The use of a service level agreement with the ICT Department. & 3.9 & 3.1 \\
\hline Increasing the portfolio of applications. & 3.9 & 3.5 \\
\hline Access to external databases through the system. & 3.4 & 2.7 \\
\hline Ability to conduct computer conferencing with colleagues. & 2.8 & 1.9 \\
\hline
\end{tabular}


Figure 1: A trace of the average performance (lower line) and importance (upper line) scores on each of the thirty eight attributes

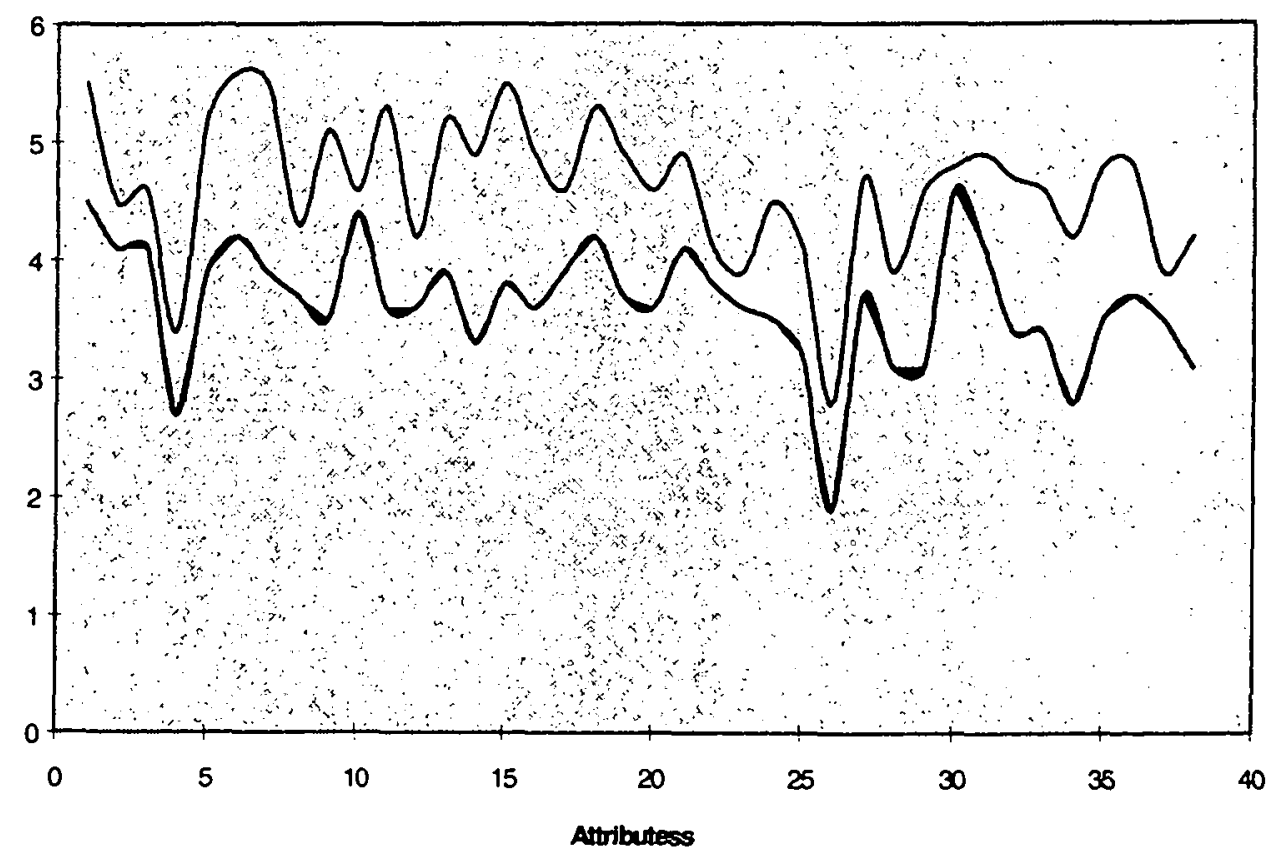

Table 2 and Figure 1 show that in all cases the average importance score was higher than the average performance score and that the two curves mirrored each other closely. What is most important is the distance between these two measures evaluated in the context of the relative importance of attributes. To this end, a "gap" measure was constructed which was the individual's performance score minus their importance score on each attribute. The gap between importance and performance on each attribute is shown in Table 3. A negative score is considered to denote the width of the "performance deficit" on each measure. 
Table 3: The ranked importance of attributes and the difference between importance and performance

\begin{tabular}{|c|c|c|}
\hline Attribute & Importance & Gap \\
\hline A high degree of technical competence in systems support staff. & 5.6 & -1.38 \\
\hline Ease of access for users to computing facilities. & 5.5 & -1.01 \\
\hline User confidence in systems. & 5.5 & -1.49 \\
\hline Fast response time from systems support staff to remedy problems. & 5.5 & -1.65 \\
\hline Provision for disaster recovery. & 5.3 & -1.67 \\
\hline Positive attitude of information systems/ICT staff to users. & 5.3 & -1.07 \\
\hline A low percentage of hardware and software downtime. & 5.2 & -1.32 \\
\hline System's response time. & 5.2 & -1.20 \\
\hline Systems responsiveness to changing user needs. & 5.1 & -1.64 \\
\hline Extent of user training. & 4.9 & -1.64 \\
\hline Participation in the planning of the system's requirements. & 4.9 & -1.39 \\
\hline Users' understanding of the system. & 4.9 & -1.09 \\
\hline Ability of the system to improve personal productivity. & 4.9 & -0.75 \\
\hline The quality of the reports delivered to the user. & 4.9 & -0.73 \\
\hline The use of Windows type software. & 4.8 & -0.23 \\
\hline Systems analysts who know the user's business. & 4.8 & -1.25 \\
\hline Flexibility of the system with regards to both data and reports. & 4.8 & -1.07 \\
\hline Users' willingness to find time to learn the system. & 4.7 & -1.02 \\
\hline Prompt processing of requests for changes to the existing systems. & 4.7 & -1.35 \\
\hline Up-to-dateness of software. & 4.6 & -0.51 \\
\hline Confidentiality of user's own data. & 4.6 & -0.13 \\
\hline $\begin{array}{l}\text { Flexibility to produce professional reports (e.g. graphics and desktop } \\
\text { publishing). }\end{array}$ & 4.6 & -0.66 \\
\hline Overall cost-effectiveness of information systems. & 4.6 & -0.99 \\
\hline $\begin{array}{l}\text { The monitoring of the ICT Department's performance in delivering services } \\
\text { to users. }\end{array}$ & 4.6 & -1.56 \\
\hline $\begin{array}{l}\text { The alignment of the information systems plan with the overall corporate } \\
\text { plan. }\end{array}$ & 4.6 & -1.17 \\
\hline Up-to-dateness of hardware. & 4.5 & -0.32 \\
\hline Documentation to support training. & 4.5 & -0.97 \\
\hline The degree of personal control users have over their systems. & 4.3 & -0.58 \\
\hline Procedures for avoiding software piracy. & 4.2 & -0.58 \\
\hline Short lead times for the development of new systems. & 4.2 & -1.32 \\
\hline The measurement of benefits derived by the user from the system. & 4.2 & -1.00 \\
\hline Ability of the system to enrich the working experience of the user. & 4.1 & -0.31 \\
\hline Help with database or data model development. & 4.1 & -0.89 \\
\hline Standardisation of hardware. & 3.9 & -0.24 \\
\hline The use of a service level agreement with the ICT Department. & 3.9 & -0.85 \\
\hline Increasing the portfolio of applications. & 3.9 & -0.43 \\
\hline Access to external databases through the system. & 3.4 & -0.69 \\
\hline Ability to conduct computer conferencing with colleagues. & 2.8 & -0.90 \\
\hline
\end{tabular}

Table 3 was used to identify those measures which were rated both as important and as having a high importance-performance gap ("performance deficit"). An arbitrary importance score of 4.7 or above and an importance-performance gap score of -1.20 or above were taken as cut-off points and eleven of the thirty eight measures were isolated. These attributes are listed below (ranked by importance): 
- A high degree of technical competence in systems support staff

- User confidence in systems

- Fast response time from systems support staff to remedy problems

- Provision for disaster recovery

- A low percentage of hardware and software downtime

- System's response time

- Systems responsiveness to changing user needs

- Extent of user training

- Participation in the planning of the system's requirements

- Systems analysts who know the user's business

- Prompt processing of requests for changes to the existing systems

The outcome of this analysis was the isolation of those measures deemed most important by users where the organisation's IS/T department has the highest performance deficit.

\section{FACTOR ANALYSIS OF THE IMPORTANCE-PERFORMANCE SCORES}

The interpretation of the thirty eight importance, satisfaction and gap scores proved to be somewhat difficult and so it was decided to apply a data reduction technique (factor analysis) to the importance and performance data in an attempt to:

- identify the latent structure of the satisfaction and importance scores;

- create a set of composite variables (factors) to make the analysis more understandable; and,

- provide a base for the comparative analysis of the six local authorities.

The results of the factor analysis of the importance measures are shown in Table 4.

Table 4: "Importance" factors and their related attributes

\begin{tabular}{|l|c|}
\hline Factor 1: Systems support & $\begin{array}{c}\text { Importance } \\
\text { score }\end{array}$ \\
\hline Increasing the portfolio of applications. & 3.9 \\
\hline Flexibility of the system with regards to both data and reports. & 4.8 \\
\hline Systems analysts who know the user's business. & 4.8 \\
\hline Short lead times for the development of new systems. & 4.2 \\
\hline Prompt processing of requests for changes to the existing systems. & 4.7 \\
\hline Factor 2: Training and service monitoring & 4.6 \\
\hline The monitoring of the ICT Department's performance in delivering services to users. & 4.5 \\
\hline Documentation to support training. & 4.9 \\
\hline Extent of user training. & \\
\hline Factor 3: Support staff & 5.3 \\
\hline Positive attitude of information systems/ICT staff to users. & 5.5 \\
\hline User confidence in systems. & 5.6 \\
\hline A high degree of technical competence in systems support staff. & \\
\hline Factor 4: Up-to-datedness & 4.6 \\
\hline Up-to-dateness of software. & 4.5 \\
\hline Up-to-dateness of hardware. & 4.3 \\
\hline Factor 5: Enhancing personal effectiveness and alignment & 4.6 \\
\hline Ability of the system to improve personal productivity. & 4.6 \\
\hline Overall cost-effectiveness of information systems. & 4.9 \\
\hline The alignment of the information systems plan with the overall corporate plan. & \\
\hline Factor 6: Job enrichment and control & \\
\hline Ability of the system to enrich the working experience of the user. & \\
\hline The degree of personal control users have over their systems. & 4.3 \\
\hline
\end{tabular}




\begin{tabular}{|l|c|}
\hline Factor 7: Confidentiality and security & \\
\hline Confidentiality of user's own data. & 4.6 \\
\hline Provision for disaster recovery. & 5.3 \\
\hline Procedures for avoiding software piracy. & 4.2 \\
\hline Factor 8: System responsiveness & \\
\hline A low percentage of hardware and software downtime. & 5.2 \\
\hline System's response time. & 5.2 \\
\hline
\end{tabular}

In any data reduction process, information is inevitably lost but, in the above case, the eight factors in Table 4 accounted for over $53 \%$ of the variance in the data set. Each of the factors was given a label to reflect the common characteristics of the variables which correlated most strongly with that factor. The first factor grouped together a set of variables related to increasing the portfolio of applications, increasing system flexibility, having systems analysts who understand the user's business, having short lead times and the prompt processing of requests for changing existing systems. The factor comprising these variables, accounted for over $23 \%$ of the variance in the data set. The factor to account for the next highest percentage of the total variance related to training and to the monitoring of the IS/T department's performance while the third factor related almost exclusively to the attitude and technical confidence of support staff.

A similar type of analysis was undertaken on the performance data set. However, in this case, the factors which emerged from the analysis were somewhat different from those that emerged from the importance data set - though there were some similarities.

Table 5: Performance factors and their related attributes

\begin{tabular}{|l|c|}
\hline Factor 1: Desktop and reports & Importance \\
\hline The quality of the reports delivered to the user. & 4.9 \\
\hline The use of Windows software (graphical presentation, use of mouse). & 4.8 \\
\hline Flexibility to produce professional reports (e.g. graphics and desktop publishing). & 4.6 \\
\hline Factor 2: Support staff & \\
\hline Positive attitude of information systems/ICT staff to users. & 5.3 \\
\hline Fast response time from systems support staff to remedy problems. & 5.5 \\
\hline A high degree of technical competence in systems support staff. & 5.6 \\
\hline Factor 3: Training and support & \\
\hline Help with database or data model development. & 4.1 \\
\hline Documentation to support training. & 4.5 \\
\hline Participation in the planning of the system's requirements. & 4.9 \\
\hline Extent of user training. & 4.9 \\
\hline Factor 4: Alignment & \\
\hline The alignment of the information systems plan with the overall corporate plan. & 4.6 \\
\hline Factor 5: Facilities & \\
\hline Up-to-dateness of software. & 4.6 \\
\hline Up-to-dateness of hardware. & 4.5 \\
\hline Ease of access for users to computing facilities. & 5.5 \\
\hline Standardisation of hardware. & 3.9 \\
\hline
\end{tabular}

The five factors listed in Table 5 accounted for over $49 \%$ of the variance in the data set with Factor 1 accounting for $30.8 \%$ of the total variance. The factor which accounted for the highest share of the variance related almost exclusively to reporting at the desktop as the three variables which contributed most to this factor are the quality of reports, the use of Windows type software and system flexibility to produce professional reports. The second factor on the performance data mirrored Factor 3 using the importance data with the positive attitude of ICT staff and high degree of technical competence being shared by both factors. Factor 3 on the performance data isolated variables related to training (the 
extent of user training and documentation to support training) and thus has some similarities with Factor 2 of the importance data set.

\section{THE CORRELATION AND REGRESSION ANALYSIS OF OVERALL SATISFACTION AND PERFORMANCE SCORES ON THE IMPORTANCE FACTORS INDENTIFIED BY THE FACTOR ANALSIS}

If an ICT facility is to be managed to improve the overall level of user satisfaction with that organisation, it is important to be able to assess the relative contribution of each of the eight factors to overall satisfaction. To conduct this analysis, eight new variables were constructed (labelled PFAC 1 to PFAC 8) reflecting the eight importance factors shown in Table 4. An average score for each respondent based on their performance scores was constructed for each of the attributes that were shown to load onto each importance factor. The variables constructed and their descriptions are shown below:

- PFAC1 - systems support and the effective meeting of user needs

- PFAC2 - training and service monitoring

- PFAC3 - support staff attitudes and technical competence

- PFAC4 - up-to-dateness of hardware and software

- PFAC5 - enhancing personal effectiveness and alignment

- PFAC6 - job enrichment and control

- PFAC7 - confidentiality and security

- PFAC8 - system responsiveness

The correlation of each of the above factors with the overall satisfaction score is given in Table 6 . It can be seen that PFAC3, PFAC1 and PFAC2 were most strongly correlated with users' overall view of their ICT department.

Table 6: Overall satisfaction and its relationship with the PFAC variables

\begin{tabular}{|l|c|}
\hline Factors & $\begin{array}{c}\text { Correlation with } \\
\text { overall satisfaction }\end{array}$ \\
\hline PFAC1 & $0.486^{* *}$ \\
\hline PFAC2 & $0.400^{* *}$ \\
\hline PFAC3 & $0.585^{* *}$ \\
\hline PFAC4 & $0.300^{* *}$ \\
\hline PFAC5 & $0.310^{* *}$ \\
\hline PFAC6 & $0.257^{* *}$ \\
\hline PFAC7 & $0.309^{* *}$ \\
\hline PFAC8 & $0.190^{* *}$ \\
\hline
\end{tabular}

** significant at the $5 \%$ level

Regression analysis was then used to explain statistically overall satisfaction with the organisations' ICT department and its delivery of services by reference to individuals' scores on the constructed PFAC variables. The output of the regression analysis (using the backwards elimination procedure ${ }^{16}$ ) to explain users' overall satisfaction with their ICT department is shown below:

$$
\underset{(t=4.14)}{\mathrm{OS}}=\underset{(t=4.38)}{0.78}+\underset{(t=10.10)}{0.25 \mathrm{PAC} 1}
$$$$
R^{2}=0.365
$$

\footnotetext{
${ }^{16}$ By using backwards elimination, the regression analysis begins with an equation comprising all the variables included in the initial regression set (the eight factors). Variables which are found to have little explanatory power are then successively excluded until the most parsimonious model is derived.
} 
The above equation shows that PFAC3 (Support Staff) and PFAC1 (Systems Support) largely explain the overall user satisfaction with the IS/T department and the services it provides. PFAC3 (support staff attitudes and technical competence) explained most of the variation in the overall satisfaction variable. However, as the $\mathrm{R}^{2}$ derived from the equation was only 0.365 this implies that the explanation of overall satisfaction is somewhat more complex than our most parsimonious regression model would suggest.

The analysis has revealed that the thirty eight importance attributes can be collapsed into eight factors which collectively account for $53.4 \%$ of the total variance in the data set. The eight factors were then used to construct composite variables with the objective of examining the explanatory power of performance of these variables on a respondent's overall level of satisfaction with the organisation's ICT Department. It was discovered that two composite variables - systems support and support staff accounted for almost $40 \%$ of the variation in overall satisfaction with the organisation's ICT department and its delivery of an IS/T service. These factors comprised the following raw variables:

- Positive attitude of information systems/ICT staff to users.

- User confidence in systems.

- A high degree of technical competence in systems support staff.

- Increasing the portfolio of applications.

- Flexibility of the system with regards to both data and reports.

- Systems analysts who know the user's business.

- Short lead times for the development of new systems.

- Prompt processing of requests for changes to the existing systems.

Of most importance here is the finding that a positive attitude of IS/T staff, user confidence in systems and a high degree of technical competence in support staff emerge as the three most powerful variables which need to be acted upon to secure a high level of user satisfaction with the overall delivery of IS/T services in the UK local government setting.

\section{A COMPARISON OF THE SIX LOCAL AUTHORITIES AND THEIR PERFORMANCE ON THE IMPORTANCE FACTORS}

In order to assess the relative strengths and weaknesses of the six local authorities within the study, an analysis of how each local authority performed on the eight composite variables derived from the factor analysis was undertaken. The mean score of each local authority on each of the eight factors was computed and the results are shown in Table 7. The data in Table 7 are shown graphically in a radar diagram (Figure 2) as departures from the overall mean of each of the eight factors.

Table 7: Local authority scores on the eight factors

\begin{tabular}{|l|r|r|r|r|r|r|r|r|}
\hline LA & \multicolumn{1}{|c|}{ PFAC1 } & \multicolumn{1}{|c|}{ PFAC2 } & PFAC3 & PFAC4 & PFAC5 & PFAC6 & \multicolumn{1}{c|}{ PFAC7 } & \multicolumn{1}{c|}{ PFAC8 } \\
\hline Banton & 2.94 & 3.34 & 3.68 & 3.49 & 3.53 & 3.33 & 3.45 & 3.51 \\
\hline Brinton & 3.89 & 3.48 & 4.24 & 4.46 & 3.89 & 4.06 & 4.23 & 4.00 \\
\hline Dunton & 3.52 & 3.25 & 4.07 & 4.13 & 3.84 & 3.50 & 4.11 & 3.73 \\
\hline Esston & 3.60 & 3.70 & 4.41 & 4.16 & 4.05 & 3.91 & 4.12 & 4.51 \\
\hline Posham & 3.32 & 3.21 & 4.14 & 4.53 & 3.51 & 4.09 & 3.74 & 3.78 \\
\hline Wrenton & 3.21 & 2.86 & 4.25 & 4.05 & 3.41 & 3.77 & 3.72 & 4.16 \\
\hline Total & 3.41 & 3.31 & 4.13 & 4.14 & 3.70 & 3.78 & 3.89 & 3.95 \\
\hline
\end{tabular}


Figure 2: Radar diagram depicting relative authority performance on the eight factors
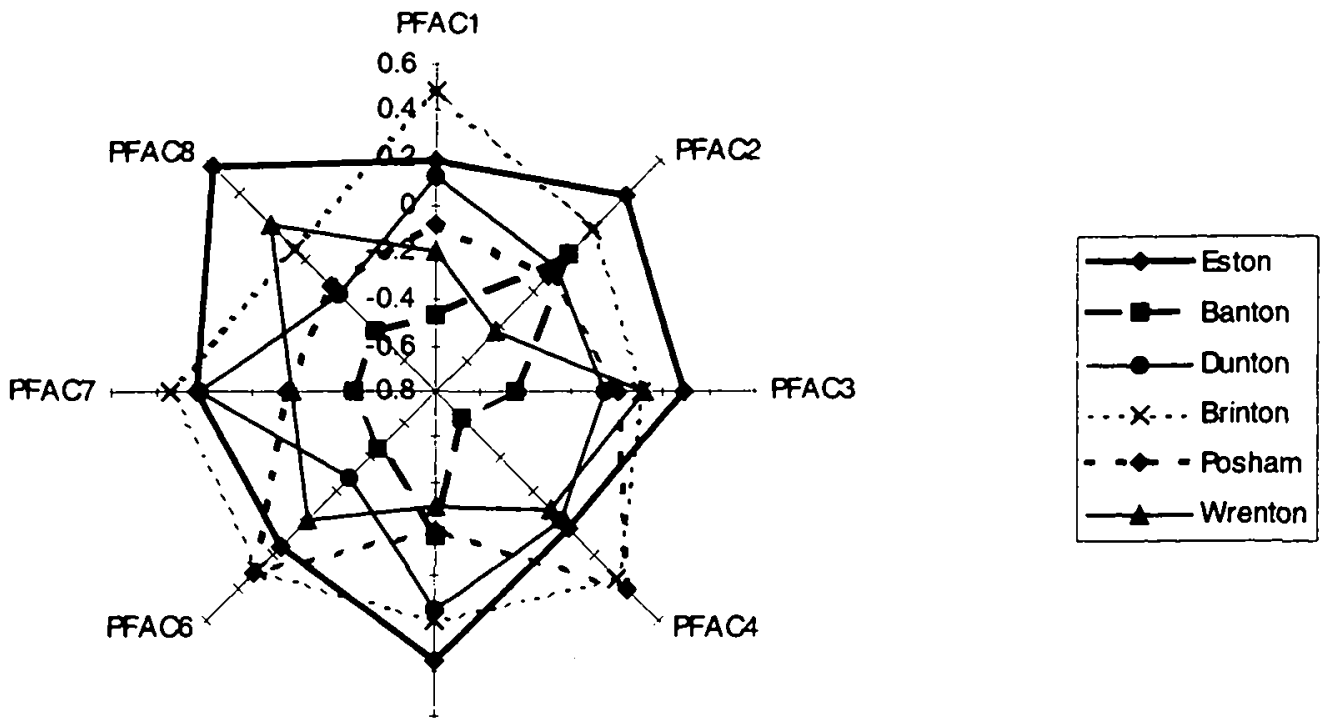

PFAC5

Table 7 and Figure 2 reveal that statistically significant differences existed between the six local authorities. (These differences were identified using ANOVA together with the Bonferroni multiple comparisons test at the $5 \%$ level of significance). From this analysis, the London Borough of Banton emerged as the local authority which fared worst on the majority of the eight factors (PFACl, 3, 4, 6, 7, 8). On PFAC4 (up-to-dateness of hardware and software), the Bonferroni procedure also showed that Banton was significantly different from the other five local authorities; on PFAC6 (job enrichment and control) and PFAC3 (support staff attitudes and technical competence) Banton was significantly different from all local authorities except Dunton; on PFACl (systems support: the prompt and effective meeting of user needs) Banton was significantly different from all local authorities other than Wrenton; and, on PFAC7 (confidentiality and security) and PFAC8 (system responsiveness) Banton was significantly different from three of the other five local authorities.

The radar diagram (included as Figure 2 where scores are plotted in terms of distance from the average scores for all local authorities) shows clearly that there were radical differences between the traces of the six local authorities. Eston and Brinton scored highly on the majority of the derived variables while Wrenton, Posham and Dunton occupied the middle ground with Banton being some distance behind.

Our analysis has revealed substantial differences across the six local authorities which, in an era when benchmarking and cross-organisational comparisons are becoming the norm, indicates the potential use of these tools both to assess the relative strength of the determinants of user satisfaction with overall performance and to expose differences between organisations on the same set of variables derived from the eight importance factors.

\section{USER INVOLVEMENT, MEETING MANAGERIAL AND OPERATIONAL NEEDS AND OVERALL SATISFACTION}

The preceding analysis has exposed significant differences between local authorities on the derived variables constructed out of the thirty eight measures. Here, we augment the analysis by looking for differences on a number of attitudinal variables about the extent to which users felt that they had been involved in influencing ICT developments; about whether users felt that ICT met their managerial and operation needs; and, users' overall opinions about the ICT department. An analysis of responses to these questions is presented in Tables $8,9,10$ and 11 . 
Table 8: Degree of user involvement in influencing ICT development as a \%

\begin{tabular}{|c|r|r|r|r|r|r|r|}
\hline & \multicolumn{1}{|c|}{ Eston } & \multicolumn{1}{c|}{ Banton } & \multicolumn{1}{c|}{ Dunton } & \multicolumn{1}{c|}{ Brinton } & Posham & Wrenton & Total \\
\hline High & 31.7 & 19.5 & 14.5 & 11.1 & 9.9 & 15.9 & 17.1 \\
\hline 2 & 29.3 & 25.6 & 18.1 & 17.3 & 21.0 & 22.0 & 22.2 \\
\hline 3 & 19.5 & 17.1 & 24.1 & 27.2 & 17.3 & 28.0 & 22.2 \\
\hline 4 & 11.0 & 15.9 & 14.5 & 11.1 & 13.6 & 12.2 & 13.0 \\
\hline 5 & 6.1 & 11.0 & 20.5 & 21.0 & 28.4 & 12.2 & 16.5 \\
\hline Low & 1.2 & 7.3 & 8.3 & 9.9 & 9.8 & 9.7 & 7.7 \\
\hline No reply & 1.2 & 3.6 & 0.0 & 2.4 & 0.0 & 0.0 & 1.3 \\
\hline
\end{tabular}

Responses on the user involvement in influencing ICT developments measure varied considerably across the six local authorities ranging from a high of $61 \%$ scoring their organisation at 1 or 2 in Eston to a low of $28 \%$ in Brinton. A regression analysis of this variable with the eight PFAC variables, however, has low explanatory power $\left(r^{2} 0.124\right)$. An analysis of the inter-relationship between the degree of user involvement and overall satisfaction does reveal that the independence hypothesis must be rejected and that user involvement is a strong component in building overall satisfaction (chi square score of 185.8 with 36 degrees of freedom).

Table 9: How well does ICT meet managerial needs as a \%

\begin{tabular}{|c|r|r|r|r|r|r|r|}
\hline & \multicolumn{1}{|c|}{ Eston } & \multicolumn{1}{c|}{ Banton } & Dunton & \multicolumn{1}{l|}{ Brinton } & \multicolumn{1}{c|}{ Posham } & Wrenton & \multicolumn{1}{c|}{ Total } \\
\hline High & 7.3 & 6.0 & 12.3 & 2.4 & 0.0 & 0.0 & 4.7 \\
\hline 2 & 42.7 & 16.9 & 16.0 & 30.5 & 27.7 & 25.3 & 26.5 \\
\hline 3 & 23.2 & 19.3 & 40.8 & 32.9 & 37.3 & 39.8 & 32.2 \\
\hline 4 & 18.3 & 36.1 & 24.7 & 20.7 & 16.9 & 15.7 & 22.1 \\
\hline Low & 4.9 & 16.9 & 6.2 & 9.8 & 7.2 & 15.7 & 10.1 \\
\hline No reply & 3.6 & 2.8 & 0.0 & 3.7 & 10.9 & 3.5 & 4.4 \\
\hline
\end{tabular}

Response on this measure again varied considerably from a high of $50 \%$ in Eston (scoring 1 or 2 ) to a low of $22.9 \%$ in Banton. The relationship between this variable and overall satisfaction was also relatively strong (with a chi square score of 222.7 at 36 degrees of freedom) indicating that an inability to meet managerial needs has a substantial effect on perceived overall satisfaction.

Table 10: How well does ICT meet operational needs as a $\%$

\begin{tabular}{|c|r|r|r|r|r|r|r|}
\hline & \multicolumn{1}{|c|}{ Eston } & \multicolumn{1}{c|}{ Banton } & \multicolumn{1}{c|}{ Dunton } & \multicolumn{1}{c|}{ Brinton } & Posham & Wrenton & \multicolumn{1}{c|}{ Total } \\
\hline High & 8.5 & 3.7 & 9.8 & 3.7 & 3.7 & 3.6 & 5.5 \\
\hline 2 & 47.6 & 17.1 & 32.9 & 26.8 & 41.5 & 31.3 & 32.9 \\
\hline 3 & 22.0 & 23.2 & 32.9 & 30.5 & 30.5 & 31.3 & 28.4 \\
\hline 4 & 14.6 & 32.9 & 15.9 & 25.6 & 7.3 & 18.1 & 19.1 \\
\hline 5 & 4.9 & 13.4 & 6.1 & 11.0 & 9.8 & 6.0 & 8.5 \\
\hline Low & 0.0 & 6.1 & 2.4 & 0.0 & 3.7 & 3.6 & 2.6 \\
\hline No reply & 2.4 & 3.6 & 0.0 & 2.4 & 3.5 & 6.1 & 3.0 \\
\hline
\end{tabular}

There were very strong differences between local authorities in terms of the extent to which ICT was perceived to meet the organisation's operational needs. This ranged from $56.1 \%$ (scoring 1 or 2) in Eston to $20.8 \%$ in Banton. Banton was substantially below the other five local authorities. The relationship between meeting operation needs and overall satisfaction with the ICT department was particularly pronounced (with a chi square score of 233.6 at 36 degrees of freedom). 
Table 11: Overall opinion of the ICT department in your organisation

\begin{tabular}{|c|r|r|r|r|r|r|r|}
\hline & \multicolumn{1}{|c|}{ Eston } & \multicolumn{1}{|c|}{ Banton } & \multicolumn{1}{c|}{ Dunton } & \multicolumn{1}{|c|}{ Brinton } & \multicolumn{1}{c|}{ Posham } & Wrenton & \multicolumn{1}{c|}{ Total } \\
\hline Poor & 1.2 & 6.0 & 0.0 & 0.0 & 0.0 & 0.0 & 1.2 \\
\hline 2 & 8.5 & 13.3 & 2.4 & 3.7 & 16.9 & 12.0 & 9.5 \\
\hline 3 & 13.4 & 22.9 & 18.3 & 17.1 & 7.2 & 21.7 & 16.8 \\
\hline 4 & 39.0 & 42.2 & 46.2 & 32.9 & 48.2 & 31.3 & 40.0 \\
\hline 5 & 32.9 & 13.3 & 30.5 & 43.9 & 24.1 & 31.3 & 29.3 \\
\hline Excellent & 2.4 & 0.0 & 2.4 & 2.4 & 3.6 & 0.0 & 1.8 \\
\hline No reply & 2.6 & 2.3 & 0.0 & 0.0 & 0.0 & 3.7 & 1.4 \\
\hline
\end{tabular}

Given the analysis of the three preceding variables, it is not surprising that there were substantial differences in users' overall opinion of their organisation's ICT department and its ability to deliver services to meet users' expectations. Reported satisfaction (i.e. the percentage recording a score of 5 or 6) was highest for Brinton (46.3\%) followed by Eston (35.3\%) with Banton (13.3\%) recording the lowest level of overall satisfaction by a substantial degree.

\section{AN ANALYSIS OF ATTITUDES AND THE PRODUCTION OF PERCEPTUAL MAPS}

The questionnaire gave respondents an opportunity to give their views on how they thought the effectiveness of their organisation's IS/T service could be improved. What follows is a distillation of their responses. The first phase of the exercise comprised a content analysis of the issues that respondents raised: in all seventeen themes were identified (see Table 12).

Table 12: Issues identified from the content analysis of the open ended question

\begin{tabular}{|c|l|l|}
\hline Number & Name & Description \\
\hline 1 & BSERV & Problems with the quality/level of service from ICT dept \\
\hline 2 & DATA & Data management problems \\
\hline 3 & DECENT & Need for more decentralisation \\
\hline 4 & DSKILL & ICT dept does not have the skills needed \\
\hline 5 & ECOM & e-mail and internal communications \\
\hline 6 & HWORK & Need for better access to systems \\
\hline 7 & LIAISE & Need for better user/ICT Dept liaison \\
\hline 8 & MGT & Problems with management of ICT \\
\hline 9 & OLDS & Problems with old systems \\
\hline 10 & PLAN & Concerns about ICT planning and strategy \\
\hline 11 & PROD & Productivity concerns \\
\hline 12 & RESC & Problems with resourcing \\
\hline 13 & STA & Need to standardise on softhardware \\
\hline 14 & SUPPT & Problems with support from ICT dept \\
\hline 15 & TRN & Need for better training \\
\hline 16 & UNEEDS & ICT dept does not understand user needs \\
\hline 17 & USER & Low user knowledge/skill \\
\hline
\end{tabular}

The second stage of the exercise was to construct a 2-way contingency table (Table 13) which counted the number of times the above seventeen issues were cited in each local authority. The third stage of the process used correspondence analysis (see Greenacre, 1994 for a full discussion of this technique and Remenyi and Money 1993 and 1994 for its application in IS/T strategy evaluation) to explore two themes:

- first, to identify which local authorities were alike in terms of the issues raised; and,

- second, to analyse the joint relationship between local authority and the issues raised to identify if certain issues tended to cluster around certain local authorities. 
Table 13: Contingency table of responses by the six local authorities

\begin{tabular}{|l|r|r|r|r|r|r|r|}
\hline Name & Brinton & Dunton & Posham & Banton & Wrenton & Eston & Total \\
\hline BSERV & 3 & 0 & 0 & 7 & 5 & 6 & 21 \\
\hline DATA & 0 & 0 & 4 & 2 & 1 & 6 & 13 \\
\hline DECENT & 0 & 0 & 0 & 0 & 2 & 5 & 7 \\
\hline DSKILL & 1 & 2 & 0 & 8 & 3 & 11 & 25 \\
\hline ECOM & 1 & 2 & 0 & 8 & 4 & 1 & 16 \\
\hline HWORK & 0 & 0 & 3 & 2 & 2 & 1 & 8 \\
\hline LIAISE & 2 & 0 & 0 & 5 & 5 & 4 & 16 \\
\hline MGT & 2 & 1 & 2 & 13 & 10 & 14 & 42 \\
\hline OLDS & 0 & 3 & 0 & 6 & 5 & 3 & 17 \\
\hline PLAN & 3 & 1 & 2 & 6 & 6 & 9 & 27 \\
\hline PROD & 2 & 0 & 0 & 3 & 5 & 4 & 14 \\
\hline RESC & 0 & 0 & 0 & 7 & 2 & 15 & 24 \\
\hline STA & 1 & 0 & 1 & 7 & 3 & 4 & 16 \\
\hline SUPPT & 2 & 3 & 2 & 8 & 2 & 8 & 25 \\
\hline TRN & 5 & 1 & 0 & 3 & 4 & 8 & 14 \\
\hline UNEEDS & 3 & 1 & 1 & 3 & 3 & 3 & 14 \\
\hline USER & 3 & 2 & 1 & 4 & 0 & 5 & 15 \\
\hline Sum & 28 & 16 & 16 & 92 & 62 & 107 & 321 \\
\hline
\end{tabular}

While a technical discussion of correspondence analysis is beyond the scope of this paper, the graphical output in Figure 3 was generated to explore the topics listed in Table 12. The points numbered 1-17 in Figure 3 relate to the issues listed in Table 12 and the triangles represent the locations of the six local authorities whose codes are shown in the Table 14.

Table 14: Local authority codes used in Figure 8.1

\begin{tabular}{|l|c|}
\hline Local Authority & Code \\
\hline Banton & BA \\
\hline Brinton & BR \\
\hline Dunton & DU \\
\hline Eston & ES \\
\hline Posham & PO \\
\hline Wrenton & WR \\
\hline
\end{tabular}

The graphical output of the correspondence analysis revealed that Brinton, Dunton, Banton and Wrenton tended to cluster together thus displaying a degree of similarity with Eston being a slight outlier to this group. Posham (a rural Welsh local authority), was significantly detached from this main group.

The advantage of correspondence analysis is that it allows us to explore the relationship between the rows and columns of a contingency table simultaneously. Our analysis reveals, for example, that:

- in Posham, the need for better home-working facilities and data management were viewed as being more problematic than in other local authorities;

- in Eston, the need for more decentralisation, problems with resourcing, the lack of ICT skills, the need for better training and low user skills were seen as relatively problematic 
Figure 3: Perceptual Map: local authorities and key issues

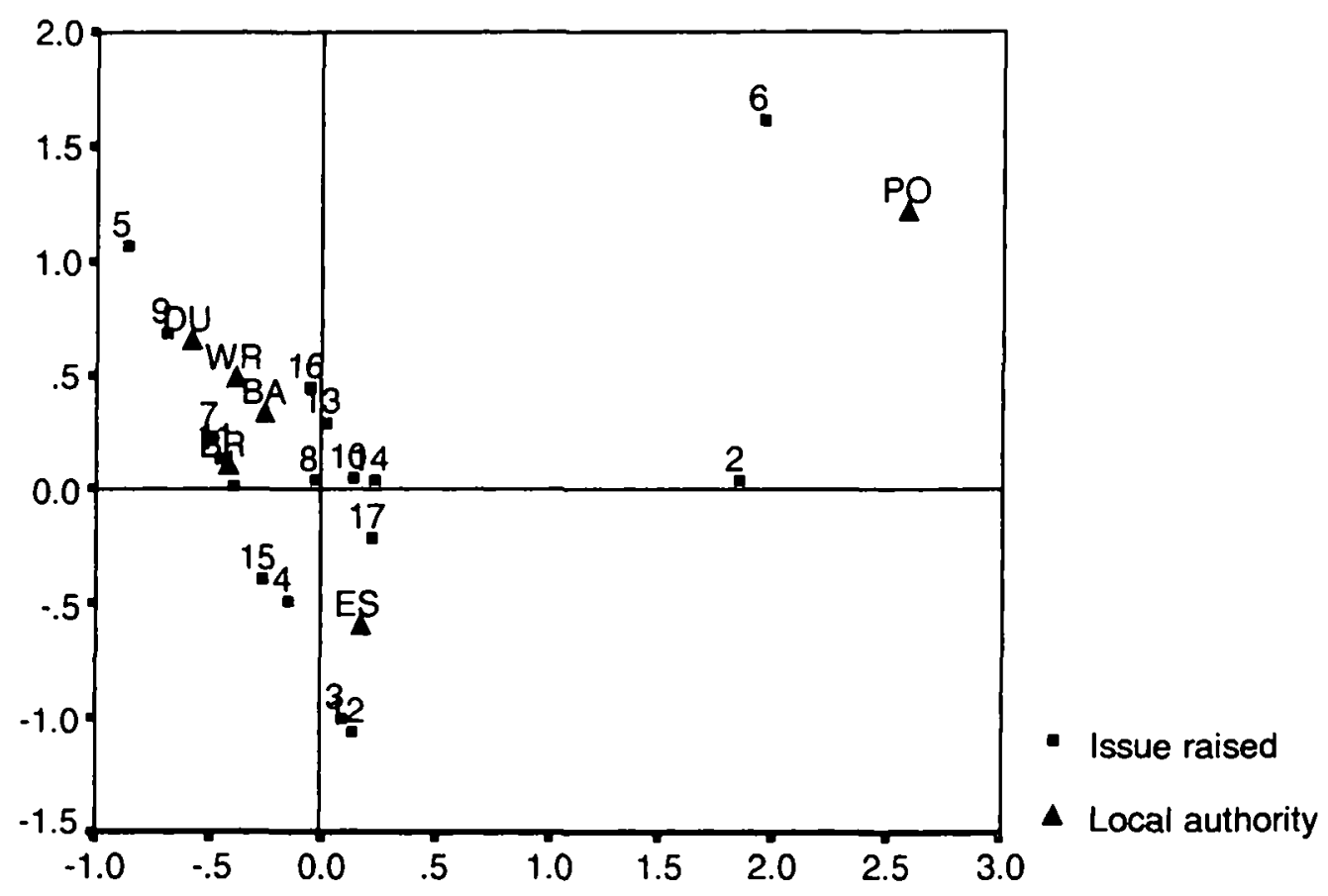

\section{Dimension 1}

\section{CONCLUSIONS}

Our research has revealed considerable variability in how users perceived their organisation's IS/T department as a deliverer of services. Analysis has revealed that there were substantial gaps between importance and performance on measures that users considered to be highly important determinants of IS/T delivery effectiveness. The use of factor analysis, regression analysis and correspondence analysis have allowed us to focus in on those issues which determine users' overall level of satisfaction with the IS/T department in their organisation. In many cases we have found that it is the softer issues such as the positive attitude of information systems/ICT staff, user confidence in systems and a high degree of technical competence in systems support staff that do most to explaining overall satisfaction with the ICT service.

The framework we have developed has been used to provide a diagnostic tool that can be used to help managers focus more clearly on those aspects of their IS/T and service delivery strategies that users perceive as important and on improving aspects of service delivery that are most undermining users' perceptions of overall performance. The analysis presented here is exploratory but highly appropriate in an era when local government ICT managers are being confronted with outsourcing and the need to benchmark their services against other local authorities and external service providers to demonstrate that they are delivering value.

This paper has been derived from a longer research paper which was presented to and then discussed with the ICT managers of the six participating local authorities. The outcomes of this session allowed us to assess the extent to which ICT managers felt our methods were robust, to discover if managers empathised with our findings (as revealed by their own research, for example, and in the context of their managerial experiences) and to elicit how managers felt our questionnaire and methodology could be refined to meet the particular circumstances of local government. This process of engagement with our research subjects allowed us to "close the circle" as a basis for improving both our questionnaire and our ability to communicate our research findings clearly and effectively. The feedback derived from the six ICT managers proved to be supportive of our findings. All ICT managers agreed on the need to develop a generic framework that would allow them to benchmark their performance against other local authorities and ICT service providers in the private sector as a means of demonstrating their capacity to 
deliver value. The research was seen as useful in that it provided a base of evidence for the continued improvement of their service. Essentially, the managers indicated that they wanted a framework that would enable them to identify best practice and enable them to understand "why the best were the best". The prevailing view was that while the questionnaire we had used was not perfect and could be made more incisive, the base of evidence we had developed had given the managers a useful insight into how an effective diagnostic tool could be developed which would give them a clear view of the issues on which they needed to focus to deliver satisfaction to the user. More important, they expressed a view that while developing and implementing a research exercise such as ours was not the "end game", it would provide them with the evidential basis for developing a constructive dialogue with users that might subsequently modify the initial research findings as clearer insights were generated from the conduct of that dialogue.

The exploration of effectiveness, particularly IS/T effectiveness, is a difficult research problem and we hope we have cast some light on this difficult issue. Our approach has shown that these issues and problems do have a definable structure and that within UK local government there are considerable inter-authority differences in performance. Perhaps most important, we have exposed that the knowledge base and user orientation of ICT staff are the most important features in explaining users' overall opinion of their ICT department as a deliverer of quality services: an effective IS/T strategy can be badly damaged if the people who deliver it do not have good "people skills".

\section{REFERENCES}

Allingham P. \& O'Connor M. (1992) MIS success: why does it vary among users? Journal of Information Technology, Vol 7, pp 160-168.

Attewell P. (1993) Technology and the Productivity Paradox, Mimeograph, City University of New York.

Banker R. \& Kemerer C F. (1991) Research undertaken on 'Performance Evaluation Metrics For Information Systems Development: A Principal-Agent Model', October, 1991.

Brynjolfsson E. (1993) The productivity paradox of information technology. Communications of the ACM, Vol. 36(12), pp 67-77.

Goss S. Miller C. \& Symons B. (1993) Exploiting the strategic potential of best value. Office of Public Management Briefing Paper. Office of Public Management. London.

Greenacre M.J. (1994) The Theory and Application of Correspondence Analysis, Academic Press, New York.

Hair, J. F., Anderson, R.E., Tatham, R.L. and Black, W. C. (1998) Multivariate Data Analysis with Readings. Fifth Edition, Prentice-Hall International Inc., New Jersey

Hitt L. \& Brynjolfsson E. (1994) The three faces of IT value: theory and evidence'. Proceedings of the Fifteenth International Conference on Information Systems, Vancouver, British Columbia, Canada, December 14-17, 1994.

Kerlinger F.N. (1969) Foundations of Behavioural Research, Holt Rinehart and Winston, London.

Lehmann D.R. (1989) Marketing Research Analysis, $3^{\text {rd }}$ Edition, Richard D. Irwin, New York.

Lester S. \& Willcocks L. (1993) How do organisations evaluate and control information systems investments? Recent UK survey evidence. Adapted from a study by the same authors: Evaluation and Control of IS Investments: Recent UK Survey Evidence, Oxford Institute of Information Management, Templeton College, Oxford, 1993.

Parasuraman A. Zeithaml V. \& Berry L. (1985) A Conceptual model of service quality and its Implications for research. Journal of Marketing, Fall 1985, pp 271-293.

Parker M.M. (1989) Information Strategy and Economics, Prentice-Hall, New York.

Peters G. (1988) Evaluating your computer investment strategy, Journal of Information Technology, Vol 3(3), pp 154-163.

Remenyi D. (1991) Introducing Strategic Information Systems Planning. National Computer Centre, Blackwell, London.

Remenyi D. \& Money, A.H. (1991) A user-satisfaction approach to IS effectiveness measurement. Journal of Information Technology, Vol 3, pp 162-175.

Remenyi D. \& Money, AH. (1993) Service quality and correspondence analysis as diagnostic tools in determining the problems associated with the effective use of computer services. Proceedings of the First European Conference on Information Systems, March 1993 
Remenyi D. \& Money A.H. (1994) Service quality and correspondence analysis in determining problems with the effective use of computer services. European Journal of Information Systems, Vol. 3(1) pp 2-12.

Remenyi D. Money A. Sherwood-Smith M. \& Irani Z, (2000) The effective measurement and management of IT costs and benefits, Butterworth Heinemann, Oxford.

Remenyi D. Sherwood-Smith $M$. with White T. (1997) Achieving maximum value from information systems: a process approach. John Wiley, Chichester.

Silk D.J. (1990) Managing IS benefits for the 1990s. Journal of Information Technology, Vol. 5, pp 132-147.

SOCITM. (1996) IT trends in local government. Society of Information Technology Management. University of Birmingham.

Willcocks L. (1991) Unpublished Chairman's Introduction to a Conference on Managing IT Investment, conducted by Business Intelligence, London, 20 May, 1991.

Wilson D. (1991) Assessing the impact of information technology on organisational performance'. In Banker R. (ed) Strategic Information Technology Management.

Kauffman P. \& Maymood M. A. (1993) Ideas Group, Harrisburg, Pennsylvania.

Worrall L. (1994) Current issues in information management: a local government perspective. Journal of Industrial Affairs, Vol. 3(2), pp 107-119.

Worrall L. (1995) Managing information in complex organisations: a local government perspective. Local Government Studies, Vol. 21(1), pp 115-129.

ACKNOWLEDEMENTS: The assistance of Martin Greenwood, consultant to the MAPIT initiative of the Society of Information Techology Managers in negotiating access to the six particpating local authorities is acknowledged. The willingness of the IT Directors of the six local authorities to participate in the research programme and their constructive comments about our research is also acknowledged. 